\title{
Misdiagnosis of HIV treatment failure based on clinical and immunological criteria in Eastern and Central Kenya
}

Sunguti Luke Joram", Gathii Paul', Kitheka Moses ${ }^{1,2}$, Bii Stanley³ ${ }^{3}$ Malonza Isaac², Gohole Allan ${ }^{1,2}$, Marwa Tom², Karimi Lilian ${ }^{4}$ and Mudany Mildred ${ }^{1,2}$

\begin{abstract}
Background: Routine laboratory monitoring is part of the basic care package offered to people living with the Human Immunodeficiency Virus (PLHIV). This paper aims to identify the proportion of PLHIVs with clinical and immunological failure who are virologically suppressed and risk being misclassified as treatment failures.

Methods: A retrospective analysis of patient viral load data collected between January 2013 and June 2014 was conducted. Of the patients classified as experiencing either clinical or immunological failure, we evaluated the proportion of true (virological) failure, and estimated the sensitivity and specificity of the immunological and clinical criteria in diagnosing true treatment failure.

Results: Of the 27,418 PLHIVs aged 2-80 years on ART in the study period, 6.8\% ( $n=1859)$ were suspected of treatment failure and their viral loads analysed. $40 \%(n=737)$ demonstrated viral suppression $(V L<1000$ copies $/ \mathrm{ml})$. The median viral load (VL) was 3317 copies/ml (IQR 0-47,547). Among the 799 (2.9\%) PLHIVs on ART classified as having clinical failure, $41.1 \%(n=328)$ of them had confirmed viral suppression. Of the $463(1.7 \%)$ classified as having immunological failure, 36.9\% $(n=171)$ had confirmed viral suppression. The sensitivity of the clinical criteria in diagnosing true failure was $61 \%$ (Cl 58\%-65\%) while that of the immunological criteria 38\% (Cl 35\%-42\%). The specificity of the clinical criteria was 34\% (Cl 30\%-39\%) while that of the immunological criteria $66 \%$ (61\%-70\%). Age below 20 years was associated with a high viral load $(p<.001)$. Sex and ART regimen were not associated with the viral load.

Conclusion: Clinical and immunological criteria alone are not sufficient to identify true treatment failure. There is need for accurate treatment failure diagnosis through viral load testing to avoid incorrect early or delayed switching of patients to second-line regimens. This study recommends increased viral load testing in line with the Kenya's ART guidelines.
\end{abstract}

Keywords: HIV, Viral load testing, Routine monitoring, Kenya

\section{Background}

In 2015, an estimated 1.5 million Kenyans were living with HIV, with 897,000 of them on antiretroviral therapy (ART) [1]. The number of HIV-infected Kenyans accessing ART is expected to rise due to increased early identification of HIV, roll out of the new ART guidelines [2], and increased adherence and retention in line with the UNAIDS 90-90-90 strategy, which has been adopted

* Correspondence: jsunguti82@gmail.com

${ }^{1}$ APHIAPLUSKAMILI, P.O. Box 2373, Embu, Kenya

Full list of author information is available at the end of the article wholeheartedly by the Kenyan government. Whilst a majority of patients on ART are expected to achieve viral suppression within one year of treatment initiation [3, 4], 5-21\% will experience treatment failure within 5 years of initiation [5-7]. Timely identification of true treatment failure in patients on ART is vitally important as it informs optimization of the use of second-line regimens and protects against unnecessary switching of ART. The Kenya Ministry of Health $(\mathrm{MOH})$ recommends the use of a combination of Tenofovir (TDF)/ Zidovudine (AZT)/Abacavir (ABC), Lamivudine (3TC) 
Table 1 WHO staging

\begin{tabular}{|c|}
\hline WHO clinical stage 1 \\
\hline 1. Asymptomatic \\
\hline 2. Persistent generalized lymphadenopathy \\
\hline WHO clinical stage 2 \\
\hline $\begin{array}{l}\text { 1. Moderate unexplained weight loss ( }<10 \% \text { of presumed or } \\
\text { measured body weight). }\end{array}$ \\
\hline $\begin{array}{l}\text { 2. Recurrent respiratory tract infections (RTIs, sinusitis, bronchitis, otitis } \\
\text { media, pharyngitis). }\end{array}$ \\
\hline 3. Herpes zoster \\
\hline 4. Angular cheilitis \\
\hline 5. Recurrent oral ulcerations \\
\hline 6. Papular pruritic eruptions \\
\hline 7. Seborrhoeic dermatitis \\
\hline 8. Fungal nail infections of fingers \\
\hline WHO clinical stage 3 \\
\hline $\begin{array}{l}\text { 1. Conditions where a presumptive diagnosis can be made on the } \\
\text { basis of clinical signs or simple investigations. }\end{array}$ \\
\hline 2. Severe weight loss ( $>10 \%$ of presumed or measured body weight). \\
\hline 3. Unexplained chronic diarrhea for longer than one month. \\
\hline $\begin{array}{l}\text { 4. Unexplained persistent fever (intermittent or constant for longer } \\
\text { than one month). }\end{array}$ \\
\hline 5. Oral candidiasis. \\
\hline 6. Oral hairy leukoplakia. \\
\hline 7. Pulmonary tuberculosis \\
\hline $\begin{array}{l}\text { 8. Severe presumed bacterial infections (e.g. pneumonia, empyema, } \\
\text { pyomyositis, bone or Joint infection, meningitis, bacteraemia). }\end{array}$ \\
\hline 9. Acute necrotizing ulcerative stomatitis, gingivitis or periodontitis. \\
\hline 10. Conditions where confirmatory diagnostic testing is necessary \\
\hline $\begin{array}{l}\text { - Unexplained anaemia }(<8 \mathrm{~g} / \mathrm{dl}) \text {, and or neutropenia }(<500 / \mathrm{mm} 3) \\
\text { and or }\end{array}$ \\
\hline - Thrombocytopenia $(<50,000 / \mathrm{mm} 3)$ for more than one month. \\
\hline
\end{tabular}

WHO clinical stage 4

Conditions where a presumptive diagnosis can be made on the basis of clinical signs or simple

investigations

1. HIV wasting syndrome

2. Pneumocystis pneumonia

3. Recurrent severe or radiological bacterial pneumonia

4. Chronic herpes simplex infection (orolabial, genital or anorectal of more than one month's duration)

5. Oesophageal candidiasis

6. Extrapulmonary TB

7. Kaposi's sarcoma

8. Central nervous system toxoplasmosis

9. HIV encephalopathy

Conditions where confirmatory diagnostic testing is necessary:

1. Extrapulmonary cryptococcosis including meningitis

2. Disseminated non-tuberculous mycobacteria infection

3. Progressive multifocal leukoencephalopathy
Table 1 WHO staging (Continued)

4. Candida of trachea, bronchi or lungs
5. Cryptosporidiosis
6. Isosporiasis
7. Visceral herpes simplex infection
8. Cytomegalovirus infection (retinitis or of an organ other than liver,
spleen or lymph nodes)
9. Any disseminated mycosis (e.g. histoplasmosis, coccidiomycosis,
penicilliosis)
10. Recurrent non-typhoidal salmonella septicaemia
11. Lymphoma (cerebral or B cell non-Hodgkin)
12. Invasive cervical carcinoma
13. Visceral leishmaniasis

and Nevirapine (NVP)/ Efavirenz (EFV) as the first-line ART regimen, with Atazanavir (ATV), Lopinavir and Ritonavir (LPV/r) currently reserved for second-line use.

Many organizations work jointly with the $\mathrm{MOH}$ in addressing the HIV epidemic in Kenya. The USAIDfunded APHIAPLUS KAMILI is one such project, supporting HIV service delivery in Eastern and Central Kenya, a catchment area of 11 counties and over nine million inhabitants. The project supports 46,264 PLHIVs, of whom 34,648 are on ART. Integrated service delivery focuses on HIV testing services (HTS), care and treatment, prevention of mother-to-child transmission (PMTCT), orphaned and vulnerable children (OVC) services, and reproductive health activities. A critical project component is laboratory networking to ensure timely collection and transport of viral load samples and a rapid turn-around time for results.

In Kenya, routine laboratory monitoring is part of the basic care package offered to people living with HIV (PLHIV), and includes tests to monitor the efficacy of ART on viral suppression (CD4 and viral load). Clinical failure is defined as occurrence of a new or recurrent WHO stage 3 or 4 disease after at least six months on ART (Table 1), while immunological failure refers to a CD4 count decrease by $>30 \%$ from peak or failure of CD4 count to rise to $>100$ cells $/ \mathrm{mm}^{3}$ after 12 months on ART [8]. Virological failure occurs when the repeat viral load remains persistently above 1000 copies/ml after three months of adherence counselling. The Kenyan Ministry of Health currently recommends the use of virological monitoring to identify treatment failure for patients on ART, with CD4 testing reserved for baseline investigation. The Ministry of Health has fully adopted routine viral load monitoring and disregarded the use of viral load for confirmatory testing in all health facilities offering HIV care and treatment in Kenya.

In this paper, we analyse viral load data collected from patients with suspected treatment failure based on 
clinical and immunological criteria between January 2013 and June 2014 from 11 APHIAPLUS KAMILI counties. We aim to demonstrate that a proportion of patients with clinical and immunological failure are virologically suppressed and yet may be misclassified as treatment failure.

\section{Methods}

\section{Study design}

This was a retrospective cross sectional analysis of secondary de-identified data collected for programmatic purposes as part of routine patient care.

\section{Setting}

The study was conducted in eight counties covered by the APHIAPLUS KAMILI project, which supports HIV care and treatment in $142 \mathrm{MOH}$ and faith-based organizations health facilities.

\section{Participants}

De-identified electronic medical records data was collected from PLHIVs who had been on ART for more than 6 months. This data was retrieved from the national electronic archive on viral load testing. Patients on second-line ART regimen and those with incomplete socio-demographic and viral load data (597) were excluded from data analysis.

From January 2013 to June 2014, samples from 1859 patients with suspected treatment failure were collected and submitted to the laboratory for viral load testing.

\section{Laboratory procedures}

During program implementation, all PLHIVs suspected of treatment failure had blood drawn for viral load testing as part of their routine laboratory monitoring while on ART. Assays used for the viral load were Abbott ${ }^{\odot}$ RT-PCR (Real-time polymerase chain reaction) (Rungis, France) for HIV-RNA and Roche Amplicor RTPCR (Maylan, France). Blood samples taken included dried blood spots (DBS) and plasma, and were sent to the Kenya Medical Research Institute (KEMRI) and National HIV Reference Laboratory (NHRL) for processing.

\section{Variables}

The variables of interest included age, sex, duration on ART, ART regimen and justification for the viral load test. The primary outcome was the patient's viral suppression. Virological failure was defined as VL > 1000 copies $/ \mathrm{ml}$, immunological failure as a CD4 fall by $>30 \%$ from peak or failure of CD4 count to rise to $>100$ cells $/ \mathrm{mm}^{3}$ after 12 months of ART, and viral suppression as $\mathrm{VL}<1000$ copies/ml.

\section{Data analysis}

Statistical analysis was conducted using the software SPSS v20 for Windows. Data was checked for consistency and extreme outliers as part of initial data cleaning. Cross-tabulations, histograms and box plots

Table 2 Baseline characteristics

\begin{tabular}{|c|c|c|}
\hline \multirow[t]{2}{*}{ Variable } & \multicolumn{2}{|c|}{ Total clients } \\
\hline & $N=1859$ & $\%$ \\
\hline \multicolumn{3}{|l|}{ Sex } \\
\hline Male & 532 & 28.6 \\
\hline Female & 872 & 46.9 \\
\hline Missing & 455 & 24.5 \\
\hline \multicolumn{3}{|l|}{ Age group } \\
\hline$<=20$ (ref) & 241 & 13.0 \\
\hline $21-40$ & 582 & 31.3 \\
\hline $41-60$ & 556 & 29.9 \\
\hline $61+$ & 65 & 3.5 \\
\hline Missing & 415 & 22.3 \\
\hline \multicolumn{3}{|l|}{ Type of Sample } \\
\hline DBS & 1653 & 88.9 \\
\hline Frozen Plasma & 188 & 10.1 \\
\hline Missing & 18 & 1.0 \\
\hline \multicolumn{3}{|l|}{ Testing lab } \\
\hline KEMRI NAIROBI & 1676 & 90.2 \\
\hline AMPATH AND NHRL ${ }^{a}$ & 183 & 9.8 \\
\hline \multicolumn{3}{|l|}{ County $^{\mathrm{b}}$ of residence } \\
\hline Embu & 279 & 15.0 \\
\hline Meru & 792 & 42.6 \\
\hline Kitui & 26 & 1.4 \\
\hline Kirinyaga & 53 & 2.9 \\
\hline Nyeri & 138 & 7.4 \\
\hline Nyandarua & 70 & 3.8 \\
\hline Kiambu & 278 & 15.0 \\
\hline Murang'a & 223 & 12.0 \\
\hline \multicolumn{3}{|l|}{ ARV regimen } \\
\hline TDF/3TC/EFV & 254 & 13.7 \\
\hline TDF/3TC/NVP & 286 & 15.4 \\
\hline AZT/3TC/NVP & 375 & 20.2 \\
\hline Other & 176 & 9.5 \\
\hline Missing & 768 & 41.3 \\
\hline \multicolumn{3}{|l|}{ Duration on ARVs } \\
\hline$<3$ years & 552 & 29.7 \\
\hline $4-6$ years & 482 & 25.9 \\
\hline $7-9$ years & 181 & 9.7 \\
\hline Missing & 644 & 34.6 \\
\hline
\end{tabular}




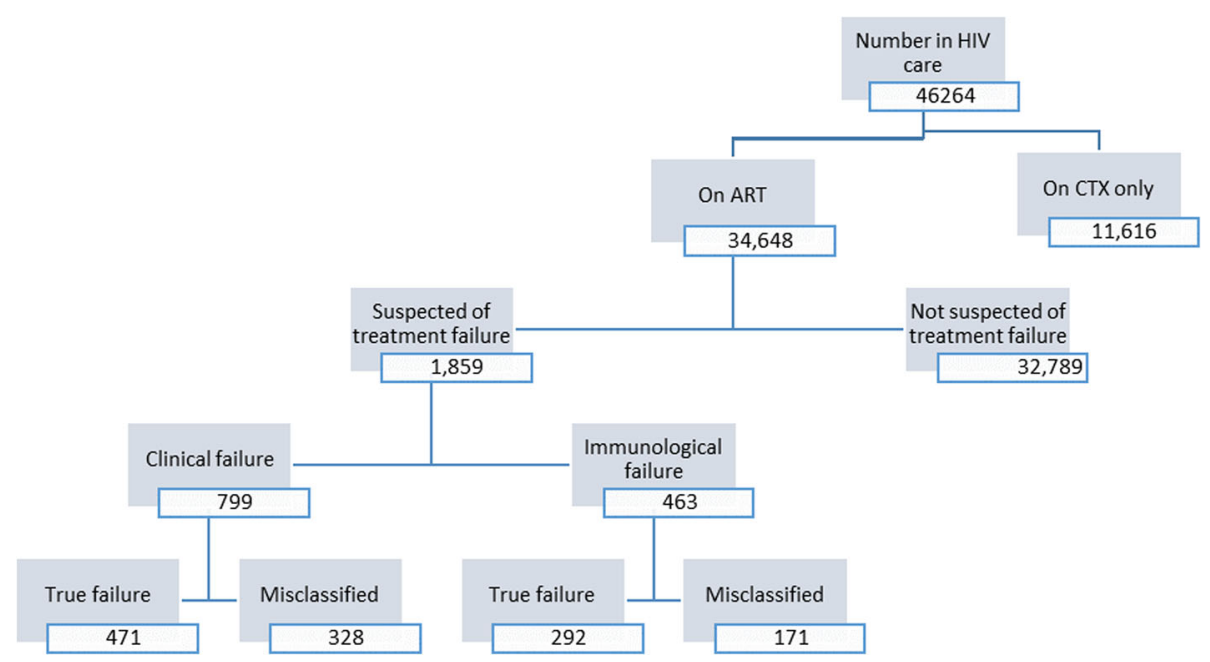

Fig. 1 Participant selection

were used to examine the data. Mean, median and standard deviation were used to describe continuous data while frequencies were used for categorical data. Association between variables was assessed through bivariate and multivariate methods. A $p$-value $<0.05$ was considered statistically significant.

\section{Results}

Viral load data from 1859 patients in eight of the eleven counties supported by the project were analysed (Table 2). Three counties were excluded because they did not have care and treatment sites supported by the project, hence no data on viral load testing. The patient median age was 38 years (IQR 30-47 years), and majority were female (62\%). The median viral load was 3317 copies/ml (047,547). The most common ART regimens used at the time of study were AZT/3TC/NVP (34\%), TDF/3TC/NVP (26\%), and TDF/3TC/EFV (23\%). The median duration on ART was 4 years (IQR 2-6 years).

The most common indication by clinicians for requesting viral load testing was clinical failure (59\%), followed by immunological failure (34\%), and others (7\%).

The proportion of patients with viral suppression was $39.5 \%$, with $60.5 \%$ experiencing virological failure. There was no significant difference between the proportion of male patients who were virally suppressed (43.1\%) and that of female patients (43.6\%). Viral suppression was highest among patients aged above 61 years $(55.4 \%)$ and lowest in those aged below 20 (23.9\%) years.

Among the 799 patients who were reported as having clinical failure, $41.1 \%(n=328)$ had confirmed viral suppression. Of the 463 patients reported as having immunological failure, 36.9\% $(n=171)$ had confirmed viral suppression (Fig. 1). The combined number for both clinical and immunological failure was 1262 . Of these, 499 (39.5\%) had confirmed viral suppression and had been misclassified.

These results indicate that $41.1 \%$ of patients in the clinical failure group were misclassified as having treatment failure, compared to $36.9 \%$ patients in the immunological failure group. The difference in proportion of misclassified patients between the two groups was, however, not statistically significant (OR 0.84 , CI $0.66-1.06)$. The sensitivity of clinical criteria in diagnosing true failure was 61\% (CI 58\%-65\%) while immunological criteria had a low sensitivity of $38 \%$ (CI 35\%-42\%). The specificity of the clinical criteria was $34 \%$ (CI $30 \%-39 \%$ ) while that of the immunological criteria was $66 \%(61 \%-70 \%)$ (Table 3$)$.

At both bivariate and multivariate levels, increase in age of the patient was associated with reduced odds of virological failure (Table 4). Associations between virological failure and sex, ART regimen and duration on ART was not found to be statistically significant.

\section{Discussion}

Viral load monitoring is routinely carried out in PLHIVs in most countries. In low income countries, viral load tests have been previously restricted to drug resistance studies and diagnosis of HIV-exposed infants, possibly due to inadequate resources. In Kenya, viral load testing is now recommended for monitoring of patients on

Table $\mathbf{3}$ Sensitivity and specificity

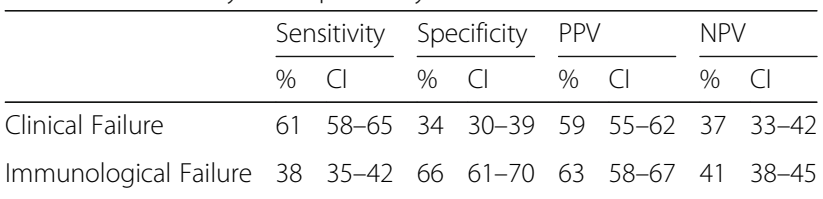


Table 4 Bivariate and multivariate analysis

\begin{tabular}{|c|c|c|c|c|c|c|c|c|}
\hline \multirow[t]{2}{*}{ Factors } & \multirow[t]{2}{*}{ COR } & \multirow[t]{2}{*}{$P$-value } & \multicolumn{2}{|c|}{$95 \%$ Cl for COR } & \multirow[t]{2}{*}{ AOR } & \multirow[t]{2}{*}{$P$-value } & \multicolumn{2}{|c|}{$95 \% \mathrm{Cl}$ for $\mathrm{AOR}$} \\
\hline & & & Lower & Upper & & & Lower & Upper \\
\hline \multicolumn{9}{|l|}{ Age group } \\
\hline \multicolumn{9}{|l|}{$<=20$ (ref) } \\
\hline $21-40$ & 0.48 & $<0.001$ & 0.35 & 0.67 & 0.48 & 0.011 & 0.27 & 0.84 \\
\hline $41-60$ & 0.32 & $<0.001$ & 0.23 & 0.45 & 0.36 & 0.001 & 0.20 & 0.64 \\
\hline $61+$ & 0.29 & $<0.001$ & 0.16 & 0.50 & 0.25 & 0.002 & 0.10 & 0.59 \\
\hline \multicolumn{9}{|l|}{ Sex } \\
\hline \multicolumn{9}{|l|}{ Male...Ref } \\
\hline Female & 0.99 & 0.89 & 0.79 & 1.22 & & 0.16 & 0.53 & 1.11 \\
\hline \multicolumn{9}{|l|}{ Sample } \\
\hline \multicolumn{9}{|l|}{ DBS...Ref } \\
\hline Frozen Plasma & 0.82 & 0.21 & 0.61 & 1.11 & \multicolumn{4}{|c|}{ omitted from the final model } \\
\hline \multicolumn{9}{|l|}{ Testing lab } \\
\hline KEMRI NAIROBI...Ref & & & & & \multicolumn{4}{|c|}{ omitted from the final model } \\
\hline AMPATH AND NHRL & 0.78 & 0.11 & 0.57 & 1.06 & & & & \\
\hline \multicolumn{9}{|l|}{ ARV regimen } \\
\hline \multicolumn{9}{|l|}{ DF/3TC/EFV...Ref } \\
\hline TDF/3TC/NVP & 1.19 & 0.33 & 0.84 & 1.67 & 1.49 & 0.11 & 0.91 & 2.42 \\
\hline AZT/3TC/NVP & 0.76 & 0.09 & 0.55 & 1.05 & 0.76 & 0.23 & 0.49 & 1.19 \\
\hline Other & 0.85 & 0.43 & 0.58 & 1.26 & 0.82 & 0.47 & 0.49 & 1.39 \\
\hline \multicolumn{9}{|l|}{ Duration on ARVs } \\
\hline \multicolumn{9}{|l|}{$<3$ years... Ref } \\
\hline $4-6$ years & 1.24 & 0.09 & 0.97 & 1.59 & 1.31 & 0.13 & 0.93 & 1.87 \\
\hline $7-9$ years & 1.01 & 0.52 & 0.72 & 1.42 & 0.86 & 0.53 & 0.54 & 1.37 \\
\hline \multicolumn{9}{|l|}{ Justification for viral load } \\
\hline \multicolumn{9}{|l|}{ Clinical......Ref } \\
\hline Immunological & 1.19 & 0.15 & 0.94 & 1.51 & 1.37 & 0.08 & 0.96 & 1.97 \\
\hline Other & 0.86 & 0.48 & 0.56 & 1.32 & 1.06 & 0.83 & 0.60 & 1.88 \\
\hline
\end{tabular}

ART, replacing CD4 testing, which has since been reserved for baseline screening to identify patients eligible for cryptococcal meningitis prophylaxis (CD4 < 100).

Our study presents data on discrepancies in classification of treatment failure based on clinical, immunological and virological criteria. Consequently, we demonstrate that the use of clinical and immunological criteria alone may result in misclassification of patients with viral suppression as treatment failure leading to unnecessary, untimely, and incorrect switching to second line regimens.

Our study adds to the literature from studies done elsewhere which also evaluated misclassification of treatment failure in patients on ART. In a prospective cohort study in Uganda, immunological criteria failed to identify all the genuine treatment failures and had a low sensitivity [9]. Studies in Kenya and Uganda by Moor et al. (2008), Kantor et al. (2009) and Mermin et al. (2011) were able to illustrate that virological monitoring is the most accurate way of identifying treatment failure as compared to clinical and/or immunological criteria [1012]. These studies are important as the use of clinical and immunological criteria alone in treatment failure identification has been associated with increased resistance to HIV $[13,14]$.

In the course of treatment of PLHIVs, virological failure occurs early, followed by immunological and clinical failure. Therefore, there is need for timely and accurate treatment failure diagnosis based on viral load testing in order to avoid early or delayed switching of patients to second-line ART regimen. Switching early to secondline regimen increases the cost burden of HIV treatment and minimizes options for subsequent regimens, should they be required [11]. On the other hand, delayed switching to a second-line regimen has been associated with increased drug resistance, morbidity and mortality [15]. 
In this study, the age of the patient was associated with virological failure. Majority of patients who had virological failure fell within the age range of 20-40 years. This data is similar to that of a study conducted in Kenya by Hassan (2014) where young age was a significant predictor for virological failure and drug resistance [16]. Young HIV-infected patients constitute a special cohort experiencing challenges such as stigma, peer pressure, adherence and discrimination [17]. This, in turn, might affect adherence on ART, increasing their chances of virological (hence treatment) failure.

Patient viral load must necessarily be interpreted with caution - viral load is affected by inter-patient variation, laboratory errors, opportunistic infections, pre-ART viral load and the ART regimen [18, 19]. These factors can cause transient viral 'blips' which could be misinterpreted as virological failure. After such blips, viral load spontaneously drops to undetectable levels without change in ART regimen. It is possible that any of these factors may have influenced the findings reported in this paper.

\section{Study limitations and strengths}

An important study limitation is that the dataset analysed was based on patients with suspected treatment failure only and hence the findings cannot be generalized to the general population of PLHIVs in care. A further limitation is that this study investigated over-diagnosis of treatment failure in the absence of viral load testing. In the absence of viral load monitoring, this study cannot investigate the full scale of true treatment failure. Finally, incomplete documentation of viral load data was a notable challenge. This could possibly be due to clinicians failing to update all the patient details at the time of requesting for the viral load test. This limitation can be overcome through mentorship sessions and onjob training.

A key strength of this study is the availability of a large sample size, making it possible to analyze variables at bivariate and multivariate levels. Data quality was high and obtained entirely from the online viral load monitoring system in Kenya.

The findings from this study add to the body of knowledge on clinical and laboratory challenges of managing HIV-infected patients in low-resource settings, and build the case for the need for viral load monitoring of patients on ART.

\section{Conclusion}

Clinical and immunological criteria when applied without viral load testing are not sufficient to definitively identify treatment failure in a timely manner. There is need for accurate treatment failure diagnosis based on viral load to avoid early or delayed switching of patients to second-line
ART, and the subsequent consequences of that untimely switching. This study recommends universal viral load testing for all HIV-infected individuals in line with Kenya's ART guidelines. Findings from this study further strengthen policy and guidelines on viral load testing as the standard reliable test to be conducted prior to switching patients from first to second line ART regimens. A viral suppression survey with genotypic resistance is needed in the future to shed more light on treatment failure.

\section{Abbreviations}

3TC: Lamivudine; ABC: Abacavir; AMPATH: Academic Model Providing Access to Healthcare; APHIAPLUS: AIDS Population and Health Integrated Assistance; People Led, people owned Leadership in all structures, Universal access to services and Sustainability.; ART: Antiretroviral therapy; ATV: Atazanavir; AZT: Zidovudine; DBS: Dried blood spots; EFV: Efavirenz; HTS: HIV testing services; IAS: International AIDS society; KEMRI: Kenya Medical Research Institute; LPY/r: Lopinavir/Rotonavir; MOH: Ministry of Health; NHRL: National HIV reference laboratory; NVP: Navirapine; OVC: Orphaned and vulnerable children; PLHIV: People Living with the human immunodeficiency virus; PMTCT: Prevention of mother-to-child transmission; RT-PCR: Reverse transcription polymerase chain reaction; TDF: Tenofovir; VL: Viral Load; WHO: World Health Organization

\section{Acknowledgements}

We acknowledge the patients being supported by the project, whose viral load samples were used in this study. We also acknowledge the Ministry of Health and the County Governments in Kenya for good partnership in HIV care and treatment. We thank the International AIDS Society for accepting this paper for poster presentation. We are grateful to the Dr. Anthony Gichangi, Dr. Mark Kabue, Dr. Eunice Omanga, Dr. Shalmali Radha Karnad of Jhpiego, and Carolyne Adalla for reviewing this manuscript.

\section{Funding}

This study was made possible by the generous support of the President's Emergency Plan for AIDS Relief (PEPFAR) and the United States Agency for International Development (USAID) under award number AID-623-A-1100008. The opinions expressed herein are those of the authors and do not necessarily reflect the views of PEPFAR, USAID or the United States Government. The authors have no conflicts of interest to disclose.

The funders had no role in study design, data collection and analysis, decision to publish, or preparation of the manuscript.

\section{Availability of data and materials}

The datasets used and/or analyzed during the current study is available from the corresponding author on reasonable request.

\section{Authors' contributions}

JSL: Study conception, data acquisition and drafting of manuscript. GP, KM, $\mathrm{KL}$ : Design, data analysis and interpretation. BS, MI, GA, MT, MM: Critical revision and final approval. All authors read and approved the final manuscript

\section{Competing interests}

The authors declare that they have no competing interests.

\section{Consent for publication}

Not applicable.

\section{Ethics approval and consent to participate}

Ethical clearance for the study was obtained from the Johns Hopkins School of Public Health Institutional Review Board. A waiver from obtaining informed consent was given by the Johns Hopkins School of Public Health Institutional Review Board. The request for the waiver was because all patient data was abstracted from files and records with no direct patientresearcher interaction. No administrative permission was required for review of EMR data as this was part of the routine de-identified program data. 


\section{Meetings}

This study was presented as a poster at the 8th IAS Conference on HIV Pathogenesis, Treatment and Prevention (IAS 2015) held in Vancouver, British Colombia, Canada, on 20 July 2015.

\section{Publisher's Note}

Springer Nature remains neutral with regard to jurisdictional claims in published maps and institutional affiliations.

\section{Author details}

'APHIAPLUSKAMILI, P.O. Box 2373, Embu, Kenya. ${ }^{2}$ Jhpiego, an affiliate of Johns Hopkins University, Nairobi, Kenya. ${ }^{3}$ USAID, Nairobi, Kenya. ${ }^{4}$ Ministry of Health, Meru County, Kenya.

Received: 5 December 2016 Accepted: 23 May 2017

Published online: 02 June 2017

\section{References}

1. National AIDS Control Council (NACC), Kenya. Kenya AIDS Response Progress Report 2016. Nairobi, NACC. October 2016. Available at: http://nacc or.ke/wp-content/uploads/2016/11/Kenya-AIDS-Progress-Report_web.pdf

2. Ministry of Health; National AIDS and STI Control Program (NASCOP). Guidelines on Use of Antiretroviral Drugs for Treating and Preventing HIV Infection: A rapid advice, 2014. Available at: https://aidsfree.usaid.gov/sites/ default/files/tx_kenya_2014.pdf.

3. Elul B, Basinga P, Nuwagaba-Biribonwoha H, Saito S, Horowitz D, Nash D, et al. High levels of adherence and viral suppression in a nationally representative sample of HIV-infected adults on antiretroviral therapy for 6, 12 and 18 months in Rwanda. 2013;8(1):e53586.

4. Kabugo C, Bahendeka S, Mwebaze R, Malamba S, Katuntu D, Downing R, et al. Long-term experience providing antiretroviral drugs in a fee-for-service HIV clinic in Uganda: evidence of extended virologic and CD4+ cell count responses. J Acquir Immune Defic Syndr. 2005;38(5):578-83.

5. Hamers RL, Wallis CL, Kityo C, Siwale M, Mandaliya K, Conradie F, et al. HIV-1 drug resistance in antiretroviral-naive individuals in sub-Saharan Africa after rollout of antiretroviral therapy: a multicentre observational study. Lancet Infect dis. 2011;11(10):750-9.

6. Karlsson A, Bjorkman P, Bratt G, Ekvall H, Gisslén M, Sonnerborg A, et al. Low prevalence of transmitted drug resistance in patients newly diagnosed with HIV-1 infection in Sweden 2003-2010. PLoS One. 2012;7(3):e33484.

7. Stadeli KM, Richman DD. Rates of emergence of HIV drug resistance in resource-limited settings: a systematic review. Antivir Ther. 2013;18(1):115.

8. Ministry of Health; National AIDS and STI Control Program (NASCOP). Guidelines for antiretroviral therapy in Kenya, 4th edition, 2011. Available at: http://healthservices.uonbi.ac.ke/sites/default/files/centraladmin/ healthservices/Kenya\%20Treatment\%20Guidelines\%202011.pdf

9. Reynolds SJ, Nakigozi G, Newell K, Ndyanabo A, Galiwongo R, Boaz I, Quinn TC, Gray R, Wawer M, Serwadda D. Failure of immunologic criteria to appropriately identify antiretroviral treatment failure in Uganda. AIDS (London, England). 2009;23(6):697.

10. Moore DM, Awor A, Downing R, Kaplan J, Montaner JS, Hancock J, et al. CD4+ T-cell count monitoring does not accurately identify HIV-infected adults with virologic failure receiving antiretroviral therapy. J Acquir Immune Defic Syndr. 2008;49(5):477-84.

11. Kantor R, Diero L, DeLong A, Kamle L, Muyonga S, Mambo F, et al. Misclassification of first-line antiretroviral treatment failure based on immunological monitoring of HIV infection in resource-limited settings. Clin Infect dis. 2009;49(3):454-62.

12. Mermin J, Ekwaru JP, Were W, Degerman R, Bunnell R, Kaharuza F, et al. Utility of routine viral load, CD4 cell count, and clinical monitoring among adults with HIV receiving antiretroviral therapy in Uganda: randomised trial. BMJ. 2011;343:d6792

13. Calmy A, Ford N, Hirschel B, Reynolds SJ, Lynen L, Goemaere E, de la Vega FG, Perrin L, Rodriguez W. HIV viral load monitoring in resource-limited regions: optional or necessary? Clinical Infectious Diseases. 2007:44(1):128-134.

14. Rawizza HE, Chaplin B, Meloni ST, Eisen G, Rao T, Sankalé J-L, Dieng-Sarr A Agbaji O, Onwujekwe DI, Gashau W. Immunologic criteria are poor predictors of virologic outcome: implications for HIV treatment monitoring in resource-limited settings. Clinical Infectious Diseases. 2011;53(12):1283-1290.
15. Anderson AM, Bartlett JA. Changing antiretroviral therapy in the setting of virologic relapse: review of the current literature. Current HIV/AIDS Reports. 2006;3(2):79-85.

16. Hassan AS, Nabwera HM, Mwaringa SM, Obonyo CA, Sanders EJ, de Wit TFR, Cane PA, Berkley JA: HIV-1 virologic failure and acquired drug resistance among first-line antiretroviral experienced adults at a rural HIV clinic in coastal Kenya: a cross-sectional study. AIDS research and therapy 2014, 11(1):9.

17. Dowshen N, D'Angelo L. Health care transition for youth living with HIV/ AIDS. Pediatrics. 2011:128(4):762-771.

18. Jonesa LE, Perelson AS: Opportunistic infection as a cause of transient viremia in chronically infected HIV patients under treatment with HAART. Bulletin of mathematical biology 2005, 67(6):1227-1251.

19. Widdrington J, Payne B, Medhi M, Valappil M, Schmid ML: The significance of very low-level viraemia detected by sensitive viral load assays in HIV infected patients on HAART. Journal of Infection 2011, 62(1):87-92.

\section{Submit your next manuscript to BioMed Central and we will help you at every step:}

- We accept pre-submission inquiries

- Our selector tool helps you to find the most relevant journal

- We provide round the clock customer support

- Convenient online submission

- Thorough peer review

- Inclusion in PubMed and all major indexing services

- Maximum visibility for your research

Submit your manuscript at www.biomedcentral.com/submit
Biomed Central 